\title{
Comparative Study of Hydrogen Electrooxidation on Gold and Platinum in Solutions Containing Perchlorate Ion
}

\author{
Alicia E. Von Mengershausen ${ }^{1}$, Norma V. Almeida', Mariela N. Barzola ${ }^{1}$, Jorge O. Zerbino², \\ Sylvia M. Esquenoni' ${ }^{1}$ Maria G. Sustersic ${ }^{1}$ \\ ${ }^{1}$ Facultad de Ingenieria y Ciencias Agropecuarias, Universidad Nacional de San Luis, San Luis, Argentina \\ ${ }^{2}$ Comision de Investigaciones Cientificas de la Provincia de Buenos Aires, La Plata, Argentina \\ Email: sustersic@gmail.com
}

Received 11 October 2013; revised 12 January 2014; accepted 21 March 2014

Copyright @ 2014 by authors and Scientific Research Publishing Inc.

This work is licensed under the Creative Commons Attribution International License (CC BY).

http://creativecommons.org/licenses/by/4.0/

(c) (i) Open Access

\begin{abstract}
The electrooxidation of hydrogen on platinum and gold electrodes is comparatively described in this paper. The reaction is faster on platinum than on the gold surface, because the reactive diffuses inside of the gold metal. This process is complicated with the lift of surface reconstruction of the (100) plane, which allows the fast penetration of the $\mathrm{H}$ atoms through the more open surface. The diffusion limiting current is then discontinued and the current falls. On platinum, the current fall occurs simultaneously with the metal oxide formation. It is assumed that the hydrogen helps the adsorbed $\mathrm{OH}$ group formation, which is the first step of metal oxidation, and it has been called "incipient hydrous oxide" (IHO). Current begins to fall slowly at the (IHO) potential. At higher potential the current falls abruptly.
\end{abstract}

\section{Keywords}

Hydrogen, Electrooxidation, Gold, Platinum, Perchlorate Ion

\section{Introduction}

Study of the electrooxidation of hydrogen is of great importance because of their application in oxygen/hydrogen fuel cells. Oxygen electrochemical dissolution is much slower than that of the hydrogen. Therefore, it provides the highest overpotential on the cell operation [1]. It is known that platinum is the metal on which the hydrogen electrode has the highest exchange current density [2]-[5]. However, the kinetic of the hydrogen electrode, because of its speed, suffers interference of material transport and kinetic parameters obtained in acid me- 
dium are not reproducible [6]-[8]. Moreover, it is necessary to know the mechanism of the reaction to elucidate the application site of the electrocatalyst in porous media, due to the high cost of the noble metal. On gold, atomic hydrogen diffuses into the metal and its surface concentration is very low [9]-[12]. On both metals potential assisted reconstruction surface occurs [13]. The reappearance of the structure $(1 \times 1)$ affects the reaction kinetics. This influence is notably manifested in the case of gold. On the surfaces of both metals, the diffusion of the reagent controls the reaction in conditions of low hydrogen partial pressure [12] [14].

\section{Experimental}

A Pyrex glass cell with two compartments is used. In the main compartment the working electrode and the auxiliary electrode are placed. They are constructed with spectroscopic gold or platinum sheets of $5 \mathrm{~N}$ purity. Apparent area ratio between the auxiliary and working electrode (RHE) is approximately 40/1. A reversible hydrogen electrode, which is used as reference electrode, is placed in the lateral compartment connected to the central compartment by a Luggin capillary. The potentials shown in the figures are referred to the RHE. The electrolyte is a solution of $1 \mathrm{M}$ perchloric acid prepared with analytical reagent and degassed with nitrogen of high quality. To study the influence of $\mathrm{pH}$ on the reaction, solutions are prepared by mixing perchloric acid and lithium perchlorate, maintaining constant the ionic strength. Rectified hydrogen is used as a reactive. Partial pressure is controlled by mixing the reactive with nitrogen and controlling the flow of each gas by a Matheson flowmeter. The experiments were performed using a LYP potentiostat connected with a ramp function generator of the same brand. The voltammograms were recorded with an Allen XY recorder.

\section{Results and Discussion}

To study the electrooxidation of hydrogen $(\mathrm{H})$, sweeps between 0.075 and $1.5 \mathrm{~V}$ on platinum and between 0.1 to $1.7 \mathrm{~V}$ on gold in the absence of the reagent are performed. Then, hydrogen is bubbled at a given partial pressure during the necessary time to obtain a constant $\mathrm{H}$ concentration in the electrolyte (30 min). The Scan is then repeated with different potential limits for each metal. The variables studied are the gas partial pressure and the potential sweep rate, V. For both types of surface a linear relationship between the maximum current and the partial pressure approximately fits. The linearity between peak current and square root of the potential sweep rate is found only at low partial pressures, manifesting a diffusion control for those conditions, as shown in Figure 1. For partial pressures greater than $0.1 \mathrm{~atm}$ a mixed control probably occurs [12]. On gold, the current drops to zero when the surface reconstruction of (100) plane lifts. On platinum, hydrogen collaborates with the formation of $\mathrm{OH}$ groups on the surface, decreasing the current smoothly at potential greater than $0.7 \mathrm{~V}$ and dropping sharply at $0.8 \mathrm{~V}$, potential at which the metal oxide appears. The current is anodic in the forward and in the reverse scans for both metals, indicating a strong reaction shift to the right. In the case of Pt, the intermediary is the adsorbed atomic H. For gold, it has been postulated a diatomic cation with a positive charge [12].

With platinum, sweeping between 0.075 and $1.5 \mathrm{~V}$ at $0.1 \mathrm{~V} / \mathrm{sec}$, the classic profile of $\mathrm{Pt} / \mathrm{HClO}_{4}$ system is obtained. The hydrogen and oxygen monolayer's formation current can be observed. For studying the oxidation reaction of $\mathrm{H}_{2}$, the sweep between 0.075 and $0.8 \mathrm{~V}$ has been done. At first, the scanning in the absence of the reagent is performed. Then, $\mathrm{H}_{2}$ is bubbled at a given partial pressure for a time enough to obtain constant $\mathrm{H}_{2}$ concentration in the solution. Then, the scan to $0.8 \mathrm{~V}$ is repeated. It is observed the same voltammogram profile, but moved up as if he had added a constant current. The current difference between the two records was plotted against partial pressure, obtaining a relation that can be approximately fitted to a straight line as shown in Figure 2. The great mass transport contribution on the reaction speed is then evident.

Figure 3 shows voltammetric records obtained with platinum in perchloric acid saturated with hydrogen gas. Blank has been included (no reagent), for comparison purposes. The current is anodic in direct and inverse cycles. Up to $0.75 \mathrm{~V}$, the current is constant and presents typical fluctuations due to convection interference with the media, as it held the gas bubbling through the experience. At potentials higher than $0.75 \mathrm{~V}$, the current drops slowly and this is due to the presence of hydrogen which collaborates with the formation of incipient hydrated oxide [15], which takes place by the adsorption of $\mathrm{OH}$ groups. At higher potentials, the platinum oxide formed during direct cycle is not completely reduced and for this reason, the hydrogen oxidation current is lower in the reverse cycles than that in the direct cycles. For potential lower than $1.1 \mathrm{~V}$, the reverse current cycle is the same as in direct cycles, indicating that the $\mathrm{OH}$ groups were removed from the surface at potentials lesser than $1.1 \mathrm{~V}$ in the reverse cycle. On the gold, (Figure 4), the metal oxide formation catalyzes the reaction and then the current is higher in 


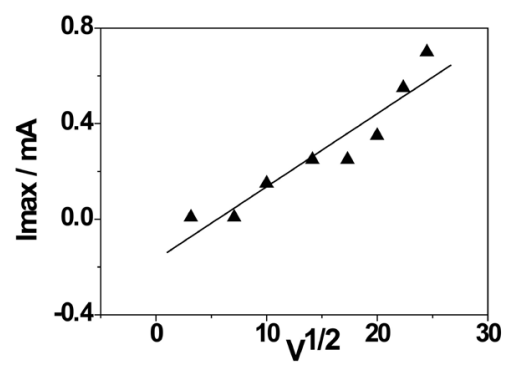

Figure 1. Plot of the maximum current of hydrogen oxidation in function of the square root of the potential sweep rate. Platinum electrode. $\mathrm{H}$ partial pressure: $0.1 \mathrm{~atm}, \mathrm{t}=25^{\circ} \mathrm{C}$.

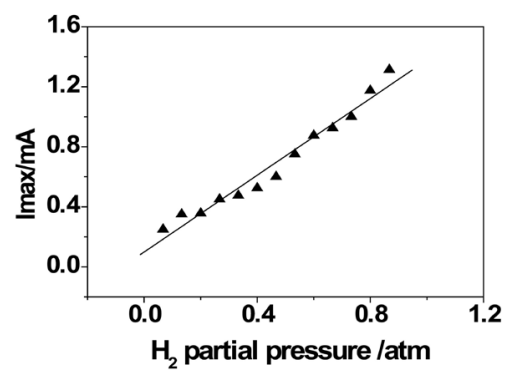

Figure 2. Representation of hydrogen limiting current as a function of its partial pressure. The straight line is the linear fit of the experimental points set. Platinum electrode.

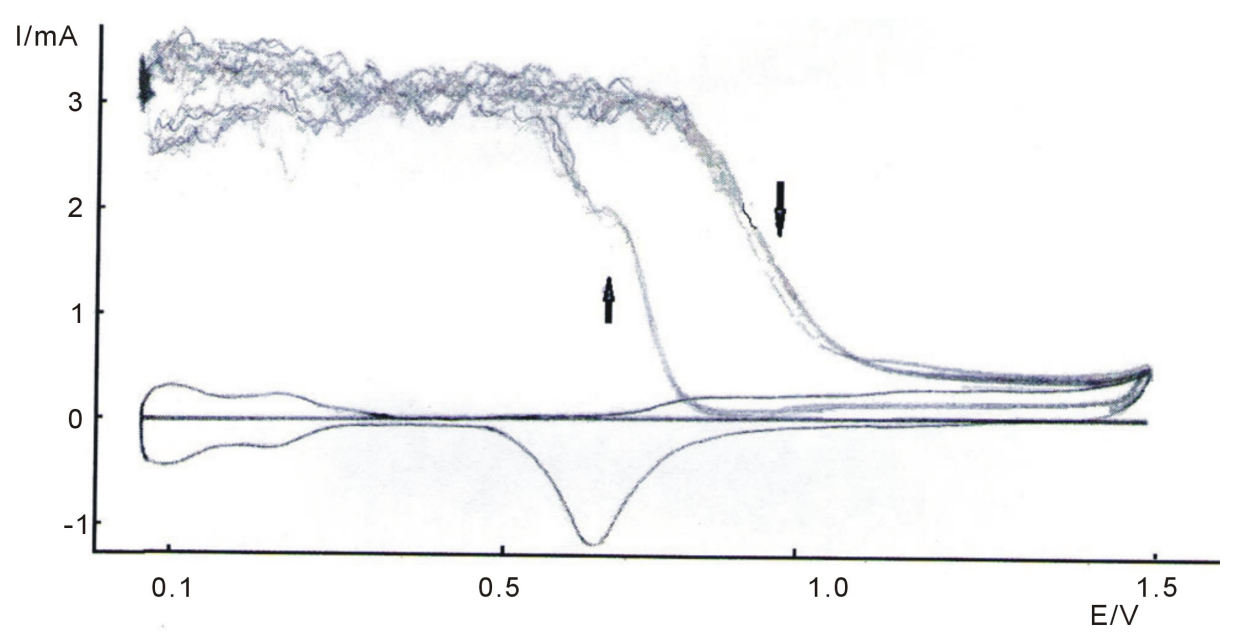

Figure 3. Voltammetric records obtained with platinum electrode in perchloric acid saturated with hydrogen gas, sweepning between 0.075 and $1.5 \mathrm{~V} ; \mathrm{v}=0.1 \mathrm{~V} / \mathrm{s}, \mathrm{t}=25^{\circ} \mathrm{C}$.

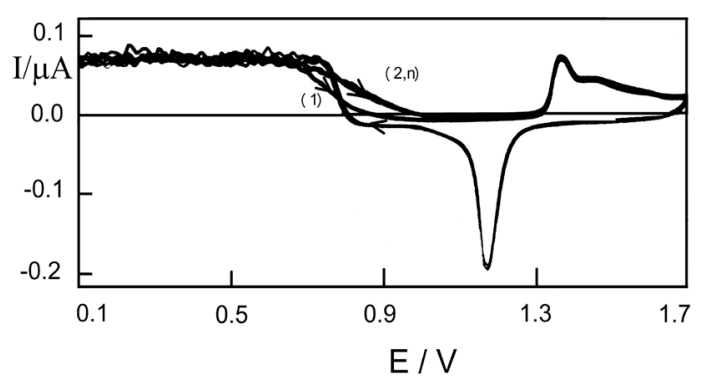

Figure 4. Voltammetric records obtained with gold electrode in perchloric acid saturated with hydrogen gas, sweepning between 0.1 and $1.7 \mathrm{~V}, \mathrm{v}=0.1 \mathrm{~V} / \mathrm{s}, \mathrm{t}=25^{\circ} \mathrm{C}$. 


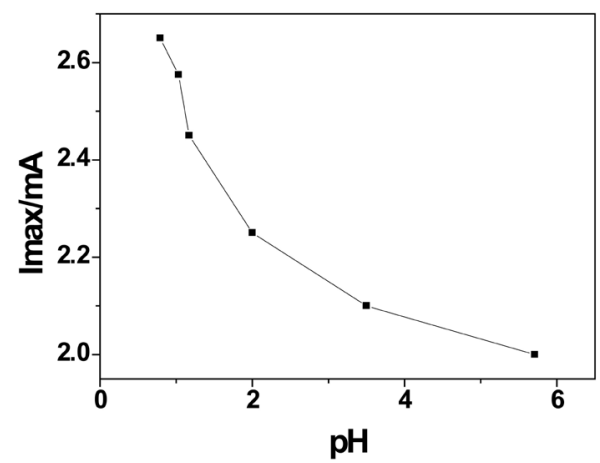

Figure 5. Plot of the $\mathrm{H}$ limiting current vs. pH. Platinum electrode. $\mathrm{T}=25^{\circ} \mathrm{C}$.

the reverse cycle than that in the direct cycle.

At higher $\mathrm{pH}$, the reaction current is lower, as shown in the Figure 5. The lowering the current as $\mathrm{pH}$ is increased has been observed also in previous works [2] and it shows the participation of hydrogen ions in the oxidation reaction.

\section{Conclusions}

When the partial pressure is lower than $0.1 \mathrm{~atm}$, the $\mathrm{H}$ reaction is diffusion controlled on both materials.

In addition, the reaction is strongly shifted towards the right. The current drops abruptly when the surface reconstruction of plane (100) on gold lifts. On platinum, however, the current drop coincides with the formation of metal oxide at $0.8 \mathrm{~V}$. Above this potential the contribution of both the reaction under study and the formation of the different metal oxides through the $\mathrm{OH}$ groups adsorbed is evident and the $\mathrm{H}$ oxidation is inhibited. On the other hand, sweeping the gold oxide potential region, the gold offers a more active surface for the $\mathrm{H}$ oxidation reaction.

The presence of $\mathrm{H}$ promotes the formation of both the hydrous platinum oxide and other metals oxides at higher potentials.

It is believed that under the experimental conditions the control of the hydrogen electrooxidation is diffusional. However, at higher potentials, the reactive contributes to the formation of different metal oxides through the adsorbed $\mathrm{OH}$ groups on platinum and the reaction is passivated.

\section{Acknowledgements}

The Universidad Nacional de San Luis supports this research. M.G. Sustersic is member of Consejo Nacional de Investigaciones Científicas y Técnicas. Jorge Zerbino is member of Comisión de Investigaciones Científicas de la Provincia de Buenos Aires.

\section{References}

[1] Neyerlin, K.C., Gu, W., Jorne, J. and Gasteiger, H.A. (2007) Study of the Exchange Current Density for the Hydrogen Oxidation and Evolution Reactions. Journal of the Electrochemical Society, 154, B631-B635.

[2] Bagotzky and Osetrova, N.Y. (1973) Investigation of Hydrogen Ionization on Platinum with the Help of Micro-Electrodes. Electroanalytical Chemistry and Interfacial Electrochemistry, 43, 233-249.

[3] Gasteiger, H.A., Panels, J.E. and Yan, S.D. (2004) Dependence of PEM Fuel Cell Performance on Catalyst. Journal of Power Sources, 127, 162-171.

[4] Kunimatsu, K., Uchida, H., Osawa, M. and Watanabe, M. (2006) In Situ Infrared Spctroscopic and Electrochemical Study of Hydrogen Electro-Oxidation on Pt Eletroden Sulfphuric Acid. Journal of Electroanalytical Chemistry, 587, 299-307.

[5] Markovic, N.M., Grgur, B.N. and Ross, P.N. (1997) Temperature-Dependent Hydrogen Electrochemiswtry on Platinum Low-Index Single-Crystal Surfaces in Acid Solutions. The Journal of Physical Chemistry B, 101, 5405-5413. http://dx.doi.org/10.1021/jp970930d 
[6] Markovic, N.M., Sarraf, S.T., Gasteiger, H. and Ross, P.N. (1996) Hydrogen Electrochemistry on Platinum Low-Index Single-Crystal Surfaces in Alkaline Solution. Journal of the Chemical Society, Faraday Transactions, 92, 3719-3725. http://dx.doi.org/10.1039/ft9969203719

[7] Maruyama, J., Inaba, M., Katakura, K., Ogumi, Z. and Takehara, Z. (1998) Influence of Nafion ${ }^{\circledR}$ Film on the Kinetics of Anodic Hydrogen Oxidation. Journal of Electroanalytical Chemistry, 447, 201-209. http://dx.doi.org/10.1016/S0022-0728(98)00004-7

[8] Monterroza, A. and González Tesis, J. (2006) Estudio Cinético de la Oxidación de Hidrógeno en Electrodos de Polipirrol-Platino. Universidad Nacional de Colombia, Sede Medellín, Facultad de Minas, Medellín.

[9] Chao, F., Costa, M. and Parsons, R. (1980) SIMS Analysis of the Distribution of Hydrogen Absorbed by Gold Electrodes during the Evolution of Hydrogen. Journal of Electroanalytical Chemistry, 115, 31-44. http://dx.doi.org/10.1016/S0022-0728(80)80493-1

[10] Martins, M.E., Podestá, J.J. and Arvía, A.J. (1987) Chemical Evidence of Hydrogen Sorption Processes on Potential Cycled Gold Electrodes. Electrochimica Acta, 32, 1013-1017. http://dx.doi.org/10.1016/0013-4686(87)90026-0

[11] Sustersic, M.G., Zanon, T.A., Albano, S.G. and von Mengershausen, A.E. (2008) Deposición de Hidrógeno a Subpotencial Sobre Oro Policristalino y con Orientación Preferida. Información Tecnológica, 19, 49-60. http://dx.doi.org/10.4067/S0718-07642008000500007

[12] Sustersic, M.G., Almeida, N.V. and Von Mengershausen, A.E. (2010) Hydrogen Oxidation on Gold Electrode in Perchloric Acid Solution. International Journal of Hydrogen Energy, 35, 6063-6068. http://dx.doi.org/10.1016/j.ijhydene.2009.12.068

[13] Kolb, D.M. (1996) Reconstruction Phenomena at Metal-Electrolyte Interfaces. Progress in Surface Science, 51, 109173. http://dx.doi.org/10.1016/0079-6816(96)00002-0

[14] Sustersic, M.G., Moreno, D.E., Almeida, N.V. and Ipohorski, M. (2002) Técnica Potenciodinámica para Cambiar la Morfología Superficial del Oro. Información Tecnológica, 13, 75-80.

[15] Burke, L.D. (1994) Premonolayer Oxidation and Its Role in Electrocatalysis. Electrochimica Acta, 39, 1841-1848. http://dx.doi.org/10.1016/0013-4686(94)85173-5 